\title{
Assessment of Gender-Role Attitudes among People of Pakistan
}

\author{
Mona Aeysha Khalid \\ University of Strathclyde, Glasgow, UK \\ Email:mei3na4@gmail.com
}

How to cite this paper: Khalid, M. A. (2021). Assessment of Gender-Role Attitudes among People of Pakistan. Open Journal of Social Sciences, 9, 338-350.

https://doi.org/10.4236/jss.2021.912023

Received: November 3, 2021

Accepted: December 18, 2021

Published: December 21, 2021

Copyright $\odot 2021$ by author(s) and Scientific Research Publishing Inc. This work is licensed under the Creative Commons Attribution International License (CC BY 4.0).

http://creativecommons.org/licenses/by/4.0/

\begin{abstract}
In the traditional culture of Pakistan, women are subject to face many psychological and physical atrocities due to having a severe stereotypical perception of gender-roles. These discriminatory thoughts are expressed in the form of attitudes, traditions, norms, and beliefs. In this survey design, Gender Norm Attitude Scale has been administered being the most relevant and suitable scale to measure gender equity perceptions in Pakistan. It revealed that mostly people could not decide about their orientation towards gender; men were more inclined towards discriminatory beliefs than women; and educated ones (higher education) were less biased in their opinions than less or nearly educated (primary, high school and graduate) ones. Mostly, participants were highly educated (graduate), adults and vigilant; however, their undecidedness reveals that they are still not sure about possible side effects of gender inequity which is an alarming situation that would need future endeavours.
\end{abstract}

\section{Keywords}

Culture, Gender, Inequity, Gender-Norms, Attitude, Perceptions

\section{Introduction}

The patriarchal societies of the world are very much male oriented, and maleidentified with specific constructs of feminist and masculine roles (York, 2011), especially women in the Southeast and South Asian culture, are constantly struggling for independency and basic human rights (Lee \& Park, 2011). In the patriarchal culture of Pakistan, beliefs that support gender discrimination and gender bias are embedded in the culture. Women are thought as the traditionally feminine and men are taken as stereotypically masculine. Gender discrimination in Pakistan is very much prevalent across all regions, in all age groups and remains stable in almost all areas of life (Akram, 2018). Unequal gender roles and severe 
gender inequalities in Pakistan also predict violence against women at a significant level (Tazeen et al., 2011). Patriarchal values are embedded in society by exercising various religious and cultural norms. Religion is especially manipulated to keep the women in control, inside homes, and with extreme dependency upon male members of the family. It is evident from their physical veiling, separate sections at homes, in schools, in professional institutes, training centres, health care complexes and special shopping markets for women only (Singh, Ambarkhane, \& Venkataramani, 2016). Pakistani society is very much family oriented and revolves around the concept of "honour" which means women are responsible for the whole family's integrity, stability, harmony, and repute even if it comes through bearing assaults of all kinds, injustices, and discriminations. Though pressures of such conceptual themes vary from women to women and family to family, usually average and high-status women are better in control than below average, rural, and ignorant ones (Critelli, 2010).

It is pertinent to explore the main constituents of the concept to know about the integral meanings of the construct: traditions, customs, norms, values, beliefs, and attitudes. Generally, people use the terms, tradition, value, custom, and norm interchangeably to express the distinctive attitudes for gender roles and cannot distinguish between these constructs. Tradition, as per Sims and Stephen (2011) is a vital and dynamic feature of a culture and a learnt belief. Sim and Stephen also noted that traditions are those informally shared behaviours, customs and verbal expressions that circulate within or among groups. These expressions are of two natures: dynamic and conservative or changing and static respectively. Values are perceived as two polar dichotomies: right or wrong; good or bad; the positive or negative; the beautiful or ugly and valid or not valid (Gross, 1985: p. 12). There is no way to check their objective reality that can prove the real nature of values (Walters, 2002: p. 44). Therefore, it is practically challenging to justify them in either direction. However, it does not mean that beliefs, traditions, and values causing discrimination should be acceptable and enforceable. Halstead \& Reiss (2003) defined values as, "the principles and fundamental convictions which act as general guides to behaviour, enduring beliefs about what is worthwhile; ideals for which one strives; broad standards by which particular beliefs and actions are judged to be good, right, desirable or worthy of respect. Examples of values are love, fairness, equality, freedom, justice, happiness, security, peace of mind, truth" (p. 5). Ironically, in Pakistan, women strive for wrong, unrealistic, and abusive values (in terms of how they are implemented) that are not only desirable, rather appreciated, and are very much respected in the society. For example, a good woman is described in terms: tolerant, obedient, unselfish, calm, empathetic, reliable, compromising, coordinator, hospitable, and relationship oriented. She is always expected to perform household chores, care for her husband, children, and in-laws, and even support her family financially when the need arises. Despite performing all these duties, she always seeks her husband's (or any male family member's) permission to perform any small activity at home or outside (Tazeen et al., 2011). 
Gender roles as, "society's shared beliefs that apply to individuals on the basis of their socially identified sex" (Eagly, 2009: p. 269); are very closely related to gender stereotypes that are those attributes that an individual ascribes to a group of people (Eagly \& Mladinic, 1989). Gender roles can be further divided into two types: descriptive and prescriptive. In a descriptive aspect, it is essential to know what is required as a man or women in a particular situation whereas in a prescriptive aspect one should know about the behaviour expected or desirable (Rudman \& Glick, 2001; Eagly \& Mladinic, 1989). Both descriptive and prescriptive aspects of gender stereotypes restrict women from being accepted and excelled in the workplace (Heilman \& Parks-Stamm, 2007). In literature (Heilman \& Parks-Stamm, 2007) agency is often related to male stereotype characteristics in which men are perceived as more agentic like independent, assertive, energetic, and decisive. While being communal is always linked to female stereotype traits like friendly, concerned, obedient, selfless and passive. And it is also verified that these gender stereotypes are consistent across cultures. Attitude is defined as "a tendency to evaluate an entity with some degree of favour or disfavor" (Eagly \& Mladinic, 1989) and it can be distinguished by various types like cognition (related to thoughts and beliefs), affect (linked to feelings) and behaviour (actions). So gender stereotyping emerges in the form of thoughts and beliefs towards men and women being an attitude object and is always positively related to men and women's attitudes (Eagly \& Mladinic, 1989). It is therefore worth noting that not all gender stereotypes are subject to scrutiny. Only the gender stereotype that, "limits women's gaining of personal abilities, pursuing their professional careers, and making choices about their lives and life plans" are subject to condemn (Timmer et al., 2010) and possibly replace by new concepts of gender identity.

Like cultural norms, gender role perceptions share a strong tie with the religion as well. It has also been verified in a study that gender stereotypes, especially in Muslim, Latin American, and Black African societies, are the product of religious and cultural patterns. Such patterns often are transferred from one generation to another through values and beliefs which underlie attitudes, behaviours, and norms. Moreover, it is verified that in a culture where traditions and norms are maintained and prioritized on all other things, people follow the religion's beliefs blindly (Rhoodie, 1989: p. 54). It is also ascertained that "stereotyping, ignorance, male intransigence and social perceptions of male and female, are at the root of discrimination against women" (Rhoodie, 1989: p. 54). In a Pakistani society, a study conducted by Delavande \& Zafar (2013) found the significant impact of religious education upon the perception of gender discrimination of men who belonged to lower socioeconomic class. Moreover, in Washington DC, in 1986, at an international conference on women, it was concluded that traditional beliefs pose one of the most significant challenges to progress for women throughout the world (Rhoodie, 1989: p. 457). However, not all beliefs are subject to change or replace; some are better to preserve with dignity and respect while others would need to be modified or expel due to being toxic or unhealthy. 
In Pakistan, gender discrimination is at the highest level (Shah \& Baporikar, 2013). Most women cannot live an independent life, achieve a career of their choice, cannot exercise their right of choice, right to move freely and safely, cannot voice against the atrocities of men, cannot claim for the property right and many others alike. As per World Economic Forum (2017) Statistics, Pakistan was the lowest ranked country (148 out of 150) and second to last rank overall in the gender inequality index. Though women are entitled to some legal rights on papers under the constitution 1973, like the right of property, right to move freely, right to education or the right to marry with their consent and no discrimination based on gender; however, due to societal pressures and traditional practices, they are rarely seen in practicing those rights in real life (OECD, 2010; Fazl-E-Haider, 2018). Similarly, people acknowledge the importance of education for men and women equally; however, it is the fact that only $25 \%$ of women can receive primary education compared to $49 \%$ of men. Female literacy in urban Punjab is only two-thirds and much less in rural areas (Qadir, Khan, Medhin, \& Prince, 2011). Dagia \& Ismail (2018) reported a statistics of UN women Report in the year 1917, that states that 12 percent of Pakistani women (4.9 million) are severely deprived of fundamental human rights in the areas: child marriage, education, healthcare, and employment. More specifically, 24 percent of women from high-income households and 63 percent from impoverished backgrounds are married before they reach 18 . The most important and alarming implication of the girls' early marriages is that it presumes early pregnancy and then childbirth (Nasrullah, 2015) that ultimately stops education, career, and growth needs. Mostly women married at a young age are suspected of tolerating abuses from their in-laws and husbands. It is estimated that $42 \%$ of married women become mothers before they reach 20 (Nasrullah, 2015). In the education sector, 98.8 percent of women from rural and 29.3 percent from urban areas could not complete basic primary education. It is estimated that 74 percent of the total have less than six years of education. Same is the case with healthcare and other departments. When we see the difference between high and low socio-economic level (13.4 and 70.2 percent), it is significantly large (Dagia \& Ismail, 2018).

Male preference starts even when the woman is expecting a child. People show a substantial degree of discrimination between genders- sons are much more expected than daughters even before the birth of the child (Saeed, 2015, Shah \& Baporikar, 2013). After having a female child, celebrations of the new baby born are almost fade and gloomy (Kazmi, 2014). Some even choose to abort or infanticide (despite of it being illegal act in Pakistan constitution) a female child, and some go for a long line of babies $(7$ - 10) in the hope of having a baby boy (Shah \& Baporikar, 2013). When parents accept the fate of having a female child, then a long list of discrimination starts; discrimination in parenting practices (Saeed, 2015; Shah \& Baporikar, 2013); discrimination in offering food and facilities; discrimination in offering education and health care; discrimination in leisure activities and work available outside home; discrimination in marriage laws; dis- 
crimination in divorce laws and discrimination in social care settings.

In addition to stereotypical gender attitudes that might be culturally based, or religion based, there are some traditions, that support the stereotypical beliefs and encourage people to think more traditionally/stereotypically for distinct gender roles. Among these toxic traditions (like dowry, honour killing, early marriages, forced marriages), the most widely used, tolerated, and encouraged tradition is "Rukhsati" which means "sending off girls on the day of marriage for no return" (Wikipedia, 2021). Though there are many other traditions to discuss, we will be confined to only this tradition being highly crucial and the root cause of all other evils. Pakistan is not a welfare state where the government is responsible for its citizens living and safety. In Pakistan, parents are solely responsible to their kids' financial needs. So, to survive, one must earn, live, and support their family independently. In case of women, either they are not provided tools to get independence, or their education is not enough to support them financially; hence in both cases, they are taken as a responsibility to bring them up to send them to others home (husband's or in-laws home) to ensure their safety and living and any kind of investment on their future is taken as wastage of money and energy (Saeed, 2015). The system does not work as expected, and in case of any imbalance, women find no way to escape except to face with patience, tolerance, sacrifice, or suicide. It is the dilemma of Pakistani family life that we need to address seriously and sensibly to eradicate the problems linked with gender inequity and gender discrimination.

Researchers have already examined gender discrimination from various aspects and highlighted their implications in detail. For example, to see the sex discrimination, son preference was observed in a study conducted by Saeed (2015). In this study, logistic regression analysis was applied to see the relationship between son preference and hypothesized determinants which resulted in significant preference for having sons associated with various mediating factors like agricultural household, family type (extended/non extended), poverty, location (urban or rural), age at the time of marriage, women's education, and education of parents. It came out that women's education level is negatively associated with son's preference and women living in urban areas are more likely to wish for having a son.

In another study (Agha, Syed, \& Mirani, 2018), gender role discrimination is quite evident in the pictorial form of textbooks assigned to primary schools in Pakistan. In this study, 101 images of men and 71 images of women, illustrated in 81 pictures were analysed through thematic coding and found that women were shown as helpers to men while doing various household chores, field works, or supporting their men while working at home. The main thing is that they are not doing something out of their will and desire instead to give service to the men in their family, to perform their duty as a woman, and to oblige others being a woman.

In a study conducted by Adeel et al. (2017), gender differences in mobility rate were examined through analyzing daily trips, mode of choice, travel duration, 
and the purpose of travel. This study supported the fact that women in Pakistan, are less likely (almost half) to travel than men, thus a wide gender gap has been observed in general mobility (Adeel et al., 2017) that is linked to mediating factors like age, marital status, and socioeconomic status.

Additionally, Quayes \& Ramsey (2015), while using logistic regression models, estimated a severe gender disparity in children enrolment rates across all age groups ( 5 to $11 ; 12$ to $17 ; 18$ to 22 ). Although gender disparity was positively related to household income; yet it decreased in the middle-income household and a little increased in the richer households. It also supported the fact that overall boys are preferred for higher education than girls irrespective of the economic status of parents. In addition to that, a systematic review of documents by Hussain, Sultana, \& Shah (2011) regarding education policies in Pakistan with respect to enrolment rates of boys and girls have been documented in which it was concluded that gender disparity strongly prevailed in public schools of Pakistan than private sector ones. Similarly, in a study conducted by Sathar \& Kazi (2000), women's autonomy was assessed with respect to various variables in the rural Pakistan. The data was collected from 10 villages of the Punjab, and from each village 100 married women, 50 husbands were interviewed along with some focus group interviews. The main result from this study revealed that neither education nor economic class could enhance women's autonomy significantly.

A study conducted by Shah et al. (2013) on self-employed women (mostly illiterate) of Karachi, revealed that women are not generally encouraged to pursue a career, and if they choose some home based work, their income related needs are hardly met by their own efforts (Shah et al., 2013) as the major part of their income comes from the male members of the family. Even in the cases where women are highly educated and work outside, they feel compelled to prove their selves as a perfect housewife and responsible for childcare while being part of the labour market outside at the same time.

Therefore, it is evident that apart from social status, employment opportunities, educational background or marital status, women are generally taken as subordinate (helpers) to men throughout their lives, who hold no decision power or autonomy in family matters (Sathar \& Kazi, 2000; Nadeem \& Ahmad, 2018; Rawat, 2014). That is why they are at high risk of psychological and mental disorders (Mirza \& Jenkins, 2004; Khan \& Reza, 2010; Ali, Azam, Ali, Tabbusum, \& Moin, 2012; Khan, Rafique, Bawani, Hasan, \& Haroon, 2015). By contrast some studies (Shah \& Baporikar, 2013; Khurshid, 2016) revealed that factors like family system, women employment and education all have significant effect on gender discrimination.

Mostly studies on gender discrimination focused on the rural population (or illiterate people) where gender equity norms are almost negligible and non-existing; in this study our focus is on the highly educated population of Pakistan located in the urban areas of Punjab, where people generally are knowledgeable with highest literacy rate in the country (61\% in 2014), well equipped with modern resources and represent the highly informed subjects (Abdul et al., 2015). 


\section{Hypothesis:}

It was hypothesized that the attitudes of the people of Pakistan about gender equity would be strongly biased. People will show sex discrimination for gender roles in their attitudes. It is also assumed that the more educated the person is, the less biased his attitude would be towards gender role perceptions. And there will be strong association between the cultural norms and the gender-based attitudes of people that will be established through a thorough analysis of fundamental beliefs and values.

\section{Method}

\subsection{Participants}

In this study, adults (18+), residents of Pakistan have been randomly chosen. The sample consists of 252 participants with mean age $(\mathrm{M}=20-30$ and $S D$ $=.69)$ and education $(\mathrm{M}=3.36$ and $\mathrm{SD}=.94)$; which implies that mostly participants ages are between 20 and 30 and education level is graduate. The overall gender equity score $(M=41.23 ; S D=9.07)$, with 102 males $(\mathrm{M}=45.08$ and $S D=$ 9.60) and150 females $(M=38.71$ and $S D=7.76)$.

\subsection{Design}

This study was based on the survey design.

\subsection{Materials}

In this study, the data has been collected about the perception of equitable beliefs of gender norms through the Gender Norm Attitude Scale proposed by Waszak et al. (2001) due to the similarities found in the Egyptian and Pakistani culture (Waszak, Severy, Kafafi, \& Badawi, 2001). This scale is consisted of 14 items, and further divided into two major domains: beliefs of the equity for girls and women and beliefs of the rights and privileges of men. Some of the questions of this scale have been modified due to the cultural needs of the country (Pakistan). Each scale has also been extended through the edition of one item related to specific gender equity norm of Pakistan. In this way, a total of sixteen items were included in the questionnaire to measure the gender equity perceptions.

\subsection{Procedure}

At first, an ethical approval to collect the data through the questionnaire used in this study has been obtained from the relevant School of Ethics Committee. Then participants have been contacted for their voluntary participation in the research work. It was made sure that the data would remain anonymous and the information will not be exposed to any third party (except the researcher and supervisor). The participants who were willing to proceed further, have been sent a consent form. After having their consent, data was collected in a warm, and friendly environment. Each participant completed Gender Norm Attitude Scale modified version for the Pakistani adult population in which he/she had to 
choose one category most relevant to his/her attitude among five categories: agree, strongly agree, neutral, disagree and strongly disagree. After collecting the data, participants were debriefed about the aims and usefulness of the research project briefly. Then to analyze the data in SPSS, a total score of gender equity perception was assigned to each participant. After fully analysis of the data, the results will be discussed in the light of hypothesis proved or disproved.

\section{Results}

At first the data was analyzed for the normality assumption. It is evident from the histogram below and the Shapiro-Wilk $(p=.658)$ test that the data was normally distributed with ( $\mathrm{n}=252, M=41.23, S D=9.07$ ) (Figure 1 ).

This scale has a reliable, acceptable, and reasonably high level of Cronbach's Alpha reliability $(a=.78)$.

It is evident from a between groups independent sample t-test that males gender inequity score is significantly higher than females gender inequity score, $t$ $(184.73)=5.55, p<.001$ (two-tailed), Cohen's $d=.82$, which is a large effect size. This implies that Pakistani males $(\mathrm{M}=45.08$ and $S D=9.60)$ are much more biased in perceiving gender roles than females ( $M=38.71$ and $S D=7.76)$.

A one-way independent ANOVA showed a significant effect of education on gender equity perceptions, $F(3,248)=15.94, p<.001, h_{p}^{2}=.16$. Follow up analysis, using Tukey HSD revealed that the lowest educated group $(M=53.00$, $S D=7.99)$ had significantly higher gender inequity scores than the high school $(M=41.28,8.63)$, had significantly higher scores than the graduate level education $(M=41.72,8.53)$ and significantly higher score than the higher education $(M=39.51,8.26)$. Therefore, the level of biased gender score decreased with the increase in education level.

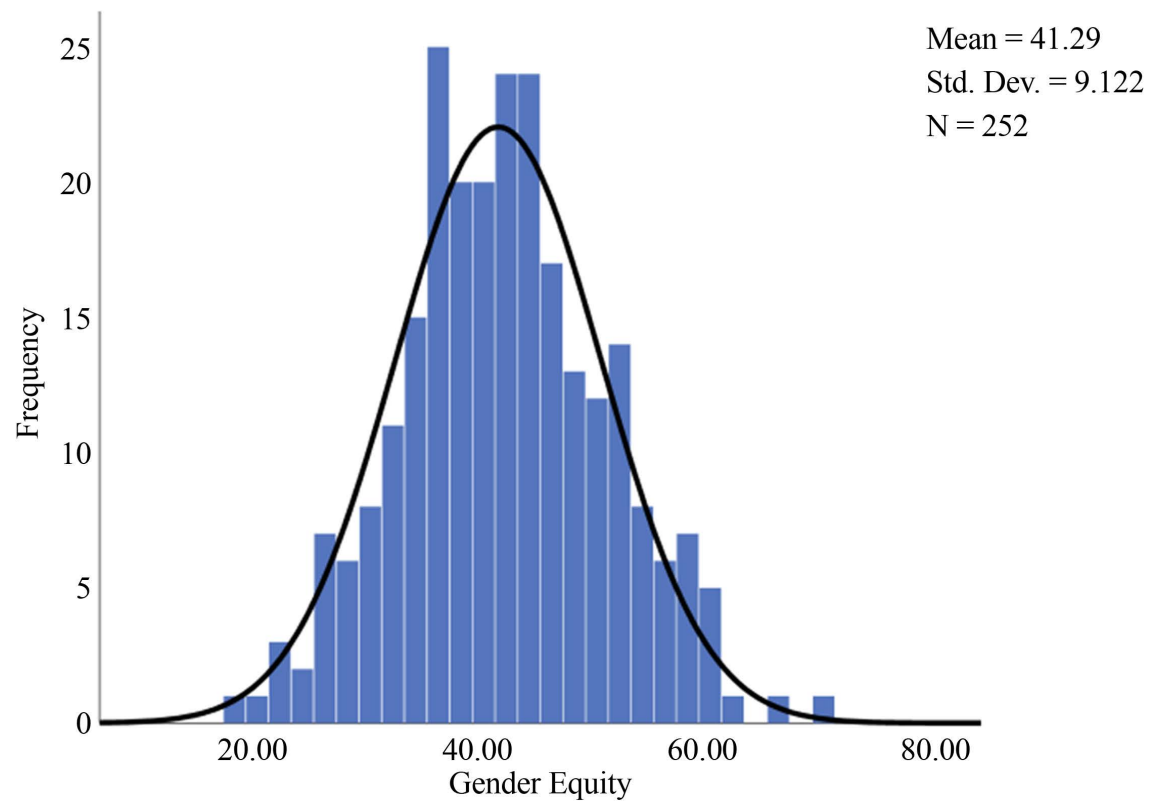

Figure 1. Histogram showing normal distribution of the data. 
The effect of marriage on the perception of gender bias is significant in the study, $t(245)=2.47, p=.014$ (two-tailed). Where married people have more biased opinions $(M=42.77 ; S D=9.34)$ than unmarried participants $(M=39.97$; $S D=8.37)$. Additionally, there is no significant difference of perception of gender roles with respect to age, $F(3,248)=.75, p=.523$.

Analyses of the content of the questionnaire revealed that there were three major groups based on gender equity scores namely: gender equity perceptions related to education; dependency upon men; gender equity in working outside and marriage tradition. It is evident from Pearson's correlation coefficients, Table 1 , that gender inequity in education is positively and significantly associated with dependency upon men $\left(r=.59, n=.252, p<.001 ; r^{2}=.35\right)$ where effect size is large. Gender inequity in education is also positively and moderately related to discriminatory perceptions in outside work $\left(r=.17, n=252 ; p<.01 ; r^{2}=.03\right)$ as well as marriage norms $\left(r=.21, n=252, p<.01 ; r^{2}=.04\right)$, with small effect size. However, outside work is not significantly related to marriage norms ( $p$ $=.053)$.

\section{Discussion}

People are not biased in their opinions about gender equity; however, it is evident that they are not totally unbiased. They seem to feel reluctant in assessing gender norms or they seem undecided upon such sensitive enquiries.

The more educated people, the less intensity in gender discrimination scores is observed. This result is consistent to other researches (Shah \& Baporikar, 2013; Tazeen et al., 2011). Likewise, in a study conducted by Saeed (2015), it was assessed that son preference was reduced with the higher level of education in women. In another study, education has a positive role on women and men for being less biased in gender role perceptions, and has a mediating role in women mobility (Nadeem \& Ahmad, 2018).

\subsection{Limitations}

The first limitation of this study is its survey design in which participants can have biased opinions due to the social desirability effect. The second limitation is that the study was based on the Likert type scale in which a neutral option was

Table 1. Pearson coefficient of correlations between gender equity scores among four constituent groups.

\begin{tabular}{lcccccc}
\hline \multicolumn{1}{c}{ Groups } & Mean & SD & 1 & 2. & 3. & 4. \\
\hline 1. Gender inequity in education & 11.05 & 4.25 & - & $.59^{* *}$ & $.17^{* *}$ & $.21^{* *}$ \\
2. Dependency upon men & 14.40 & 3.97 & - & - & $.17^{* *}$ & $.21^{* *}$ \\
3. Outside work & 9.96 & 3.22 & - & - & - & .12 \\
4. Marriage norm (sending off) & 5.88 & 1.71 & - & - & - & - \\
\hline
\end{tabular}

Note. ${ }^{\star} p<.05,{ }^{* *} p<.01, r=$ Pearson coefficient of correlation $(r=.01, p=.95)$. 
utilized. As the participants were all very well educated and most probably know the meanings underneath the statements so they could avoid accepting their biased attitudes through accepting a neutral form of agreement. This option would need further investigation and revision as it is still not so informative and conclusive.

\subsection{Recommendations}

More replication studies would be needed with the similar as well as distinct research designs (especially with longitudinal ones), with varied sample characteristics, in diverse geographical locations, especially from the rural areas where most of the biased beliefs cause gender discrimination at a large level since most of the women (63\% in 2016: 133 million) are living in rural areas and most of them are illiterate (35\%). This study has not included gender discrimination in health sectors that would also prove a great addition in understanding the subject fully.

Though fair education, equal employment resources and equal rights empowerment are basic needs to strengthen the women status in Pakistan; however, these are not the sufficient and fully influential factors. To bring equity between genders, it is more important to change the mind-set of the men as well as women. People overall need to change their belief system that perpetuate gender discrimination among their children and is ultimately revealed in the form of traditions and norms. In this connection, social media, print media and broadcast media can play an important role through depicting gender equity norms in the most positive light.

\section{Conclusion}

This study verifies the fact that gender equity norms play a great role in determining the equal status of women in various areas of life. People especially men need to be educated on the importance of equity norms in terms of fair power distribution, developmental and economic needs of society, and basic human rights. However, women can also play a great role in bringing a change in discriminatory societal norms through educating men especially their sons as well as teaching their daughters about these norms effective and ineffective dimensions.

\section{Conflicts of Interest}

The author declares no conflicts of interest regarding the publication of this paper.

\section{References}

Abdul, R., Luan, J., \& Imran, H. (2015). The Province-Wise Literacy Rate in Pakistan and Its Impact on the Economy. Pacific Science Review B: Humanities and Social Sciences, 1, 140-144. https://doi.org/10.1016/j.psrb.2016.09.001 
Adeel, M., Yeh, A. G. O., \& Zhang, F. (2017). Gender Inequality in Mobility and Mode Choice in Pakistan. Transportation, 44, 1519-1534. https://doi.org/10.1007/s11116-016-9712-8

Agha, N., Syed, G. K., \& Mirani, D. A. (2018). Exploring the Representation of Gender and Identity: Patriarchal and Citizenship Perspectives from the Primary Level Sindhi Textbooks in Pakistan. Women's Studies International Forum, 66, 17-24. https://doi.org/10.1016/j.wsif.2017.11.009

Akram, N. (2018). Women's Empowerment in Pakistan: Its Dimensions and Determinants. Social Indicators Research, 140, 755-775. https://doi.org/10.1007/s11205-017-1793-Z

Ali, N. S., Azam, I. S., Ali, B. S., Tabbusum, G., \& Moin, S. S. (2012). Frequency and Associated Factors for Anxiety and Depression in Pregnant Women: A Hospital-Based Cross-Sectional Study. The Scientific World Journal, 2012, Article ID: 653098. https://doi.org/10.1100/2012/653098 https://www.hindawi.com/journals/tswj/2012/653098/abs/

Critelli, F. M. (2010). Beyond the Veil in Pakistan. Affilia: Journal of Women and Social Work, 25, 236-249. https://doi.org/10.1177/0886109910375204

Dagia, N., \& Ismail, Z. (2018, February 14). UN Women Report Shows Worry Degree of Gender Inequality in Pakistan. The Express Tribune.

https://tribune.com.pk/story/1634815/1-un-women-report-shows-worrying-degree-ge nder-inequality-pakistan/

Delavande, A., \& Zafar, B. (2013). Gender Discrimination and Social Identity: Experimental Evidence from Urban Pakistan. Federal Reserve Bank of St Louis. https://doi.org/10.2139/ssrn.2198386

Eagly, A. H. (2009). The His and Hers of Prosocial Behavior: An Examination of the Social Psychology of Gender. American Psychologist, 64, 644-658.

https://doi.org/10.1037/0003-066X.64.8.644

Eagly, A. H., \& Mladinic, A. (1989). Gender Stereotypes and Attitudes toward Women and Men. Personality and Social Psychology Bulletin, 15, 543-558. https://doi.org/10.4324/9780203402573

Fazl-E-Haider, S. (2018). Conditions for Empowerment of Women Still Not Ripe in Pakistan. Pakistan \& Gulf Economist, 37, 4-6. https://search.proquest.com/docview/2136846597?accountid=14116

Gross, F. (1985). Ideologies, Goals, and Values. Greenwood Press Westport.

Halstead, J. M., \& Reiss, M. J. (2003). Values in Sex Education. Routledge.

Heilman, M. E., \& Parks-Stamm, E. J. (2007). Gender Stereotypes in the Workplace: Obstacles to Women's Career Progress. In S. J. Correll (Ed.), Social Psychology of Gender (Vol. 24, pp. 47-77). Emerald Group Publishing Limited. https://doi.org/10.1016/S0882-6145(07)24003-2

Hussain, K. S., Sultana, N., \& Shah, S. M. H. (2011). Critical Analysis of Gender Disparities in Education in Pakistan. Journal of Educational Research, 14. http://link.galegroup.com/apps/doc/A270815778/AONE? u=ustrath\&sid=AONE\&xid= d317aae7

Kazmi, S. H. (2014). Omni Present Gender Discrimination. Pakistan \& Gulf Economist, 33, 19-20. https://search.proquest.com/docview/1641985962?accountid=14116

Khan, K. S., Rafique, G., Bawani S. A. A., Hasan F., \& Haroon A. (2015). Social and Societal Context of Women's Mental Health, What Women Want, What They Get: Gap Analysis in Pakistan of Mental Health Services, Polices and Research. In: N. Khanlou, 
\& F. Pilkington (Eds.), Women's Mental Health (pp. 33-50). Springer. https://doi.org/10.1007/978-3-319-17326-9 3

Khan, M. M., \& Reza, H. (2010). Gender differences in Nonfatal Suicidal Behavior in Pakistan: Significance of Sociocultural Factors. Suicide and Life-Threatening Behavior, 28, 62-68. https://doi.org/10.1111/j.1943-278X.1998.tb00626.x https://onlinelibrary.wiley.com/doi/abs/10.1111/j.1943-278X.1998.tb00626.x

Khurshid, A. (2016). Domesticated Gender Equality: Women's Education \& Gender Relation among Rural Communities in Pakistan. International Journal of Educational Development, 51, 43-50. https://doi.org/10.1016/j.ijedudev.2016.08.001 https://www.sciencedirect.com/science/article/pii/S0738059316302024

Lee, J. K., \& Park, H.-G. (2011). Measures of Women's Status and Gender Inequality in Asia: Issues and Challenges. Asian Journal of Women's Studies, 17, 7-31. https://doi.org/10.1080/12259276.2011.11666106

Mirza, I., \& Jenkins, R. (2004). Risk Factors, Prevalence, and Treatment of Anxiety and Depressive Disorders in Pakistan: Systematic Review. British Medical Journal, 328, Article No. 794. https://doi.org/10.1136/bmj.328.7443.794 https://www.bmj.com/content/328/7443/794.full

Nadeem, M. T., \& Ahmad, Y. (2018). Role of University Education in Promoting Gender Equality in Community for Human Development: A Quantitative Insight. Journal of Managerial Sciences, 12, 89-98.

https://www.qurtuba.edu.pk/jms/default files/JMS/12 1/8.pdf

Nasrullah, M. (2015). Child Marriage and Its Impact on Maternal and Child Health in Pakistan. University of Bielefeld, Germany. (An Unpublished PhD dissertation) https://core.ac.uk/download/pdf/211825012.pdf

OECD (Organisation for Economic Co-Operation and Development) (2010). "Pakistan", in Atlas of Gender and Development: How Social Norms Affect Gender Equality in Non-OECD Countries. OECD Publishing.

Qadir, F., Khan, M. M., Medhin, G., \& Prince, M. (2011). Male Gender Preference, Female Gender Disadvantage as Risk Factors for Psychological Morbidity in Pakistani Women of Childbearing Age-A Life Course Perspective. BMC Public Health, 11, Article No. 745. https://doi.org/10.1186/1471-2458-11-745

http://link.galegroup.com/apps/doc/A269722242/AONE?u=ustrath\&sid=AONE\&xid= $\underline{8 \mathrm{~b} 2 \mathrm{c} 8 \mathrm{~b} 6 \mathrm{~b}}$

Quayes, S., \& Ramsey, R. D. (2015). Gender Disparity in Education Enrolment in Pakistan. Asian Economic and Financial Review, 5, 407-417.

https://doi.org/10.18488/journal.aefr/2015.5.3/102.3.407.417

https://search.proquest.com/docview/1678797188?accountid=14116

Rawat, P. S. (2014). Patriarchal Beliefs, Women's Empowerment, and General Well-Being. Vikalpa: The Journal for Decision Makers, 39, 43-56. https://doi.org/10.1177/0256090920140206

Rhoodie, E. M. (1989). Discrimination against Women a Global Survey of the Economic, Educational, Social, and Political Status of Women. McFarland \& Company, Inc.

Rudman, L. A., \& Glick, P. (2001). Prescriptive Gender Stereotypes and Backlash toward Agentic Women. Journal of Social Issues, 57, 743-762. https://doi.org/10.1111/0022-4537.00239

Saeed, S. (2015). Toward an Explanation of Son Preference in Pakistan. Social Development Issues, 37, 17-36.

https://search.proquest.com/docview/1698855492?accountid=14116

Sathar, Z., \& Kazi, S. (2000). Women's Autonomy in the Context of Rural Pakistan. The 
Pakistan Development Review, 39, 89-110. https://doi.org/10.30541/v39i2pp.89-110 http://www.jstor.org/stable/41260246

Shah, I. A., \& Baporikar, N. (2013). Gender Discrimination: Who Is Responsible? Evidence from Pakistan. Women's Studies, 42, 78-95. https://doi.org/10.1080/00497878.2013.736284

Shah, N. A., Nadeemullah, M., \& Zia, M. F. (2013). Women, Work, and Poverty: Gender-Based Factors Strengthening Feminisation of Poverty in Pakistan. Pakistan Journal of Women's Studies, 20, 87-98.

https://search.proquest.com/docview/1459404669?accountid=14116

Sims, M., \& Stephens, M. (2011). Living Folklore: An Introduction to the Study of People and Their Traditions. University Press of Colorado.

Singh, A. S., Ambarkhane, D., \& Venkataramani, B. (2016). Women-Only Markets in Pakistan. SAGE Business Cases. https://doi.org/10.4135/9781473973947

Tazeen, S. A., Gunilla, K., Raisa, G., Nargis, A., Eva, J., \& Ingrid, M. (2011). Gender Roles and Their Influence on Life Prospects for Women in Urban Karachi, Pakistan: A Qualitative Study. Global Health Action, 4, Article No. 7448.

https://doi.org/10.3402/gha.v4i0.7448

Timmer, A, Cook, R. J., \& Cusack, S. (2010). Gender Stereotyping: Transnational Legal Perspectives. Human Rights Law Review, 10, 583-586. https://doi.org/10.1093/hrlr/ngq018

Walters, G. D. (2002). Criminal Belief Systems: An Integrated Interactive Theory of Lifestyles. Praeger Publishers

Waszak, C., Severy, L. J., Kafafi, L., \& Badawi, I. (2001). Fertility Behavior and Psychological Stress: The Mediating Influence of Gender Norm Beliefs among Egyptian Women. Psychology of Women Quarterly, 25, 197-208. https://doi.org/10.1111/1471-6402.00021

WEF (World Economic Forum) (2018, December 19). Pakistan Second Worst in Gender Equality: WEF. United News of India (UNI), New Delhi, India. http://link.galegroup.com/apps/doc/A566261610/STND?u=ustrath\&sid=STND\&xid=e $\underline{61 \mathrm{f} 3084}$

Wikipedia (2021). Marriage in Pakistan. Wikipedia. https://en.wikipedia.org/wiki/Marriage in Pakistan

York, M. R. (2011). Gender Attitudes and Violence against Women. LFB Scholarly Publishing LLC. https://www.ncjrs.gov/App/Publications/abstract.aspx?ID=260376 